Andrew Tobolowsky

\title{
The Sons of Jacob and the Sons of Herakles
}

\section{The History of the Tribal System and the Organization of Biblical Identity}

[Die Söhne Jakobs und die Söhne des Herakles. Die Geschichte des Stammessystems und der Organisation biblischer Identität.]

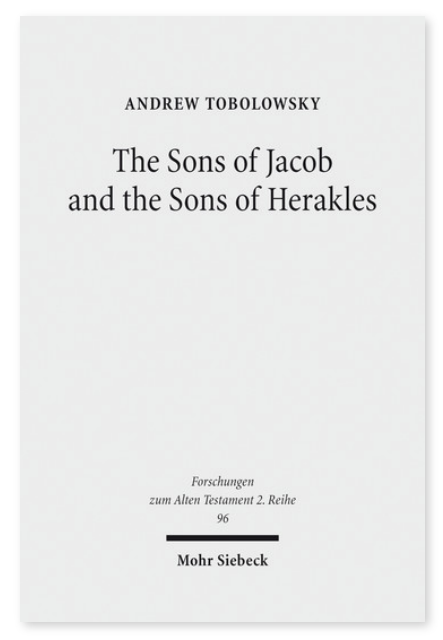

2017. IX, 283 Seiten. FAT II 96

ISBN 978-3-16-155597-8

eBook PDF 99,00€

ISBN 978-3-16-155191-8

fadengeheftete Broschur 99,00€
Veröffentlicht auf Englisch.

Andrew Tobolowsky bietet in dieser Studie einen neuen Zugang zur biblischen Beschreibung der Stämme Israels als »Söhne Jakobs«. Unterschiedliche Thesen über die frühisraelitische Geschichte und das Fehlen von Bezugnahmen auf Jakob in den meisten Erzählungen machen es unwahrscheinlich, dass dieses Verständnis Teil eines frühen Stammesdiskurses war. Stattdessen zieht Andrew Tobolowsky die auffälligen Ähnlichkeiten zwischen der Rolle, die Jakobs Kinder in der biblischen Erzählung spielen und der Rolle, die Figuren wie Hellen und Herakles in der Konstruktion griechischer Urgeschichten spielen, heran. Er schließt, dass das »stammes-genealogische« Konzept erstmals in der spätpersischen Periode entwickelt wurde, als Werkzeug für eine neu integrierte, kohärente Darstellung einer gemeinsamen ethnischen Vergangenheit; der ersten durchgängigen biblischen Vorstellung einer israelitischen Geschichte von Adam bis zum Fall Jerusalems und darüber hinaus.

Andrew Tobolowsky Born 1985; 2015 PhD in Religions of the Ancient Mediterranean; since 2016 Visiting Assistant Professor at the College of William and Mary in Williamsburg, Virginia.

https://orcid.org/0000-0001-8107-6741

\section{Jetzt bestellen:}

https://mohrsiebeck.com/buch/the-sons-of-jacob-and-the-sons-of-herakles-9783161555978?no_cache=1 order@mohrsiebeck.com

Telefon: +49 (0)7071-923-17

Telefax: +49 (0)7071-51104 